\title{
PREVALENCE OF EPISIOTOMY AND PERINEAL LACERATIONS IN A UNIVERSITY TEACHING HOSPITAL, NORTH-CENTRAL NIGERIA
}

Hembah-Hilekaan S.K ${ }^{*}$, Ojabo O.A, Audu $O^{1}$, Onche P.E, Maanongun M.T.

Department of Obstetrics and Gynecology, and Department of Epidemiology and Community Health, Benue State University Teaching Hospital, Makurdi, Nigeria. ${ }^{1}$

* Corresponding Author: Dr. S.K. Hembah-Hilekaan, Department of Obstetrics and Gynecology, Benue State University Teaching Hospital, Makurdi, Nigeria. Email: hemhilsk@yahoo.com.

Received date: April, $04^{\text {th }}$, 2018, Accepted date: May $30^{\text {th }}$, 2018. Published date: June $30^{\text {th }}, 2018$

\section{Abstract}

Episiotomy is an incision on the introitus and the perineum to increase pelvic outlet to facilitate childbirth and prevent trauma to fetal and maternal tissues. Episiotomy and perineal laceration may predispose the woman to short and long term complications. The objective of this study was to determine the prevalence of episiotomy and perineal lacerations and their associated risks factors at Benue State University Teaching Hospital, Makurdi, Nigeria. Retrospective data of all women who had spontaneous vagina delivery over a 3 year period with perineal laceration/episiotomy were reviewed. Data was obtained from the records and information on the sociodemographic variables, episiotomies, lacerations and the birth weight of infants. The associated risk factors were recorded using Statistical Package for Social Sciences version 22.Of the 636 vaginal deliveries, 85(13.4\%) had lacerations with $65(10.2 \%)$ first degree, $19(3.0 \%)$ second degree and 1(0.2\%) major laceration. Episiotomy rate was $132(20.8 \%)$. The mean parity and birth weight of infants were $2.62(\mathrm{SD}= \pm 1.83)$ and $3.1 \mathrm{~kg}(\mathrm{SD}= \pm 0.767)$ respectively. The highest number of perineal tears $69(10.8 \%)$ were in the lower age group ( $\leq 30$ years). A similar observation was noted in respect of episiotomies which rate however decreased with parity. The relationship between maternal age, parity, booking status, fetal weight and the perineal status at delivery was statistically significant $(\mathrm{P} \leq 0.05)$. Episiotomy and perineal laceration rates in our institution were low. The major risk factors were low parity, young maternal age and increasing fetal weight at birth and their presence should be an early warning sign. We advise perineal support for all women during delivery.

Keywords: Episiotomy, lacerations, Makurdi, Nigeria, Perineal, Prevalence.

\section{Introduction}

Vaginal birth is the most common mode of child birth and is usually associated with some complications, and one of the most known is perineal tear/episiotomy but there is little available data on these in our environment. Birth trauma despite all efforts to prevent it still remains an unavoidable and very real obstetric problem. It is unfortunate that nobody in the delivery room can be fully protected from this obstetric complication. ${ }^{1}$ Data on perineal lacerations and episiotomy in the developing world is relatively poor compared to the developed countries. Episiotomy and perineal lacerations may both be indications of a difficult childbirth in the second stage of labor. Episiotomy is an incision performed on the introitus and the perineum immediately prior to crowning of the fetal head to increase pelvic outlet and to facilitate childbirth and prevent fetal trauma and maternal perineal injury. It is the most common obstetric surgical operation. ${ }^{2}$ The routine use of episiotomy results in high episiotomy rate where it is practiced; however the World Health Organization recommends restrictive use over routine use. ${ }^{3}$

In England for example, episiotomies were performed on over half of all women delivering in 1980, falling to $37 \%$ in 1985 with a dramatic fall to about $20 \%$ in 1994 to $1995 .{ }^{4}$ It has been documented that $46 \%$ of low-risk nulliparous women in the UK experience episiotomy, while in the USA, a total of $30-35 \%$ of 
vaginal births include episiotomy. ${ }^{5}$ The occurrence of obstetric perineal injury is not considered substandard care because it is a known complication of vaginal delivery. However, failure to recognize anal sphincter damage and to carry out a repair may be considered substandard care. ${ }^{6}$ Obstetric perineal lacerations are classified as first to fourth degree according to Sultan and as adopted by the Internal Consultation on Incontinence and the RCOG. ${ }^{6}$ If the tear involves only anal mucosa with intact anal sphincter complex, it is referred to as bottom-hole tear and is documented separately. Severe perineal tears $\left(3^{\text {rd }}\right.$ and $4^{\text {th }}$ degree $)$ involving the anal sphincter complex and/or the anal epithelium (obstetric anal sphincter injury) are identified in $0.6-9.0 \%$ of vaginal deliveries where medio-lateral episiotomy is performed. ${ }^{7}$ Spontaneous perineal lacerations may occur on the perineum in the absence of an adequate passage. Some of the risk factors for Obstetric perineal lacerations are fetal macrosomia, malposition, shoulder dystocia, nulliparity, induction of labor, epidural analgesic, instrumental delivery especially forceps and midline episiotomy, malformation of the fetus, a rigid perineum or a combination of these factors. Most of the risk factors can not readily be used to prevent or predict the occurrence of a third and fourth degree tear. ${ }^{8}$ The sequelae of obstetric lacerations and episiotomy include dyspareunia, chronic perineal pain, urinary incontinence and fecal incontinence. ${ }^{9,} 10$ The occurrence of perineal lacerations among women may present severe risks to the mother especially among primigravida and women with identifiable risk factors and predispose the woman to short term pain, hemorrhage and possible sepsis, with some developing other long term complications. Although episiotomy may be used to prevent perineal lacerations and its complications, they are difficult to predict/ prevent. The presence of risk factors may lead to anticipation and possible intervention in order to prevent lacerations and other complications which can severely affect the quality of life of a woman. With paucity of data on these in our environment, our objective in this study was to determine the prevalence of episiotomy and perineal lacerations and the associated risks factors at BSUTH, Makurdi, Nigeria.

\section{Materials and Methods}

\section{Study area}

Benue State University Teaching Hospital (BSUTH) is a tertiary care health facility located in Makurdi, North Central Nigeria. The city also hosts a Federal Medical Centre (FMC), and General Hospital, Makurdi both renowned health facilities including many other Missionary and private hospitals. These are geared towards meeting the delivery needs of the population. This study was carried out at the Obstetrics unit of the Benue State University Teaching Hospital, Makurdi, Nigeria from January 2013 to December, 2015. During the study period, there were 636 vaginal deliveries recorded and 94 caesarean sections.

\section{Methodology}

This was a retrospective review of 636 women who delivered vaginally at the obstetric unit of BSUTH. The birth register at the hospital was used to identify all cases of vaginal delivery with episiotomy and perineal lacerations in the study period. All vaginal deliveries including breach and multifetal births were included in the study. The study was a retrospective file review of cases with information extracted from the folders and transferred onto a proforma data sheet. Subjects who had incomplete records were excluded from the study. Ethical approval was obtained from the relevant hospital committee. Information on episiotomies and perineal lacerations at birth, parity, booking status and fetal weight were analyzed by univariate and multivariate tests using SPSS version 22 statistical package.

\section{Results}

The age range of the parturients in the study population was 16 to 44 years old with a mean of 28.1 $(\mathrm{SD}= \pm 4.8$ years). There were $3.3 \%$ primigravidae with $29.2 \%$ parity one and $25.5 \%$ para two. There were $14.3 \%$ grand multiparous women with the mean parity at $2.62(\mathrm{SD}= \pm 1.83)$. The fetal weight ranged from $0.3 \mathrm{k}$ to a maximum of $5.4 \mathrm{~kg}$ with a mean of $3.1 \mathrm{~kg}(\mathrm{SD}= \pm 0.767$. Most babies weighed between $3.0-3.4 \mathrm{~kg}$ (Table 1$)$. 
Table 1: Socio-demographic characteristics of Mother and Fetus (n=636)

\begin{tabular}{|c|c|c|}
\hline Variable & Frequency & Percent \\
\hline \multicolumn{3}{|l|}{ Age of Mother (Years) } \\
\hline$\leq 20$ & 37 & 5.8 \\
\hline $21-25$ & 143 & 22.5 \\
\hline $26-30$ & 293 & 46.1 \\
\hline $31-35$ & 120 & 18.9 \\
\hline $36-40$ & 38 & 6.0 \\
\hline \multirow[t]{2}{*}{$\geq 41$} & 5 & 0.8 \\
\hline & Mean Age 28.1 years $(S D= \pm 4.8$ ) years & \\
\hline \multicolumn{3}{|l|}{ Parity } \\
\hline Nulliparous & 21 & 3.3 \\
\hline Para 1 & 186 & 29.2 \\
\hline Para 2 & 161 & 25.3 \\
\hline Para 3 & 100 & 15.7 \\
\hline Para 4 & 77 & 12.1 \\
\hline \multirow[t]{2}{*}{ Para 5 and above } & 91 & 14.3 \\
\hline & Mean parity $2.62(\mathrm{SD} \pm 1.83)$ & \\
\hline \multicolumn{3}{|l|}{ Booking status } \\
\hline Unbooked & 113 & 17.8 \\
\hline Booked & 523 & 82.2 \\
\hline \multicolumn{3}{|l|}{ HIV status } \\
\hline Non-Reactive & 555 & 87.3 \\
\hline Reactive & 81 & 12.7 \\
\hline \multicolumn{3}{|l|}{ Fetal weight } \\
\hline$\leq 2.4$ & 84 & 13.2 \\
\hline $2.5-2.9$ & 97 & 15.3 \\
\hline $3.0-3.4$ & 227 & 35.7 \\
\hline $3.5-3.9$ & 175 & 27.5 \\
\hline \multirow[t]{2}{*}{$\geq 4.0$} & 53 & 8.3 \\
\hline & Mean fetal weight: $3.10( \pm 0.757) \mathrm{Kg}$ & \\
\hline
\end{tabular}

Table 2: Maternal and fetal socio-demographic characteristics by maternal perennial status at delivery

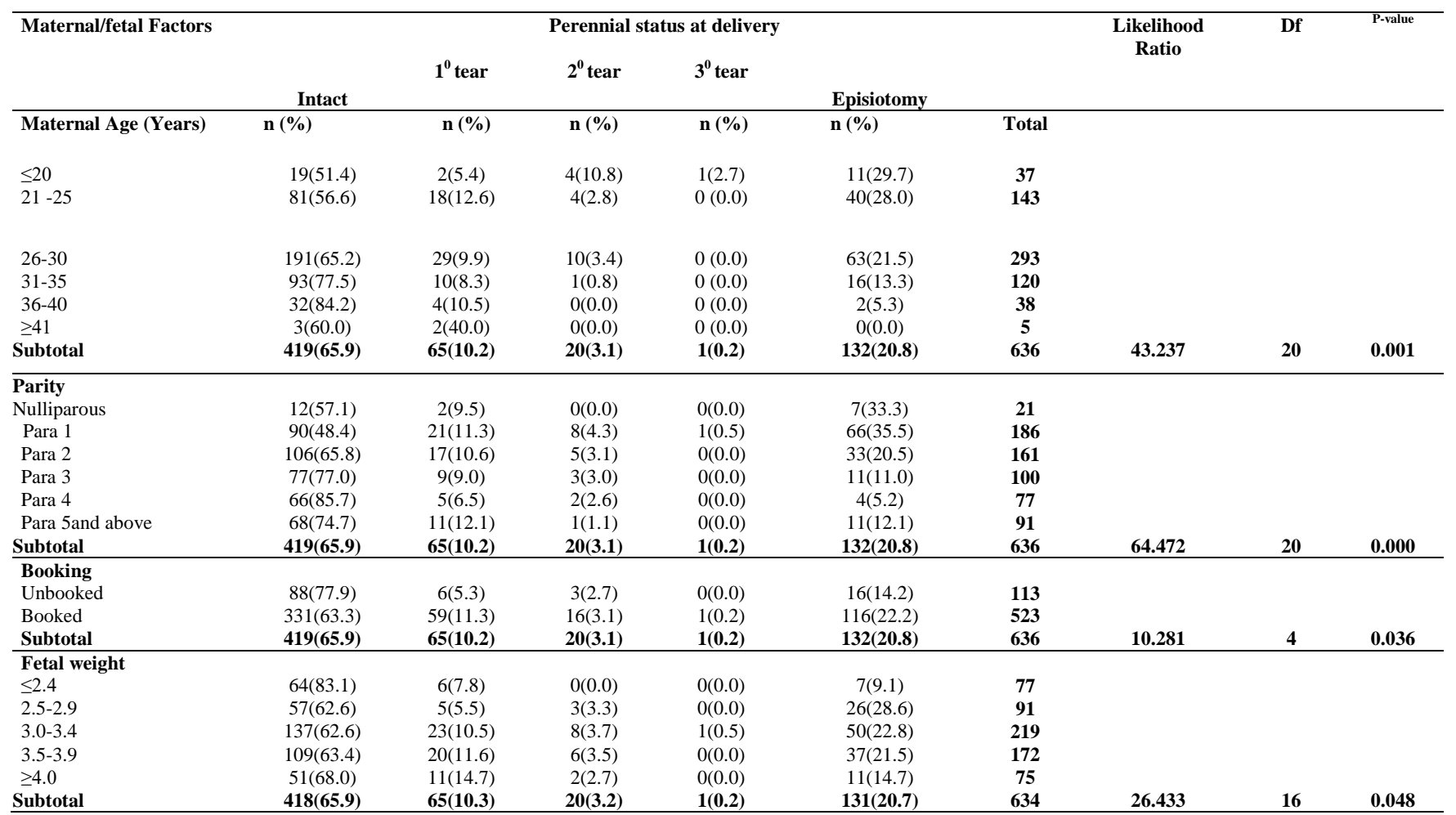

The relationship between the maternal age, the parity, booking status, fetal weight and the outcome (perennial tear) were statistically significant ( $p<0.05$ ). 


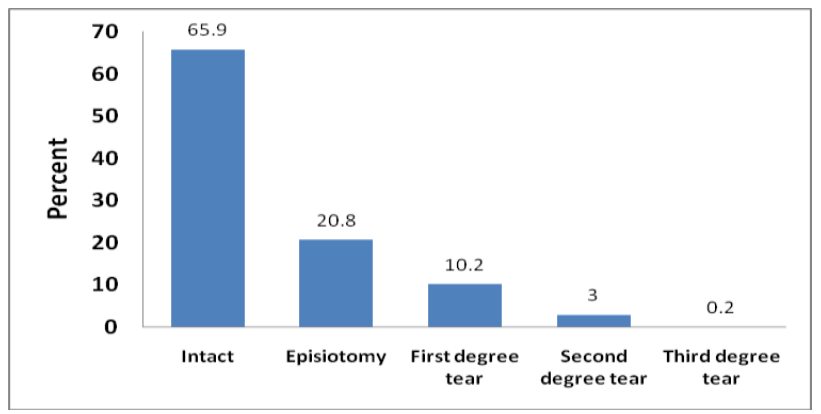

Figure 1: Distribution of perennial tear/ episiotomy during delivery

During the study period, 636 had vaginal deliveries out of a total of 730 (94 caesarean section) deliveries at the facility. Of the total vaginal deliveries, $85(13.4 \%)$ had lacerations, with $65(10.2 \%)$ first degree tears and $19(3.0 \%)$ second degree lacerations. Only $1(0.2 \%)$ had a third degree laceration. There were $4(0.63 \%)$ cases of instrumental deliveries found (3 Vacuums and 1 Forceps). All the 3 Vacuum assisted births experienced perineal trauma with 2 first degree lacerations and one episiotomy, while the only forceps delivery had episiotomy. There were $132(20.8 \%)$ of the parturients delivering at the facility who had episiotomy (fig.1). Most of the women (74.4\%) in this study were 30 years and below. The highest number $69(10.8 \%)$ of perineal lacerations were seen in the lower age group ( $\leq 30$ years) and in the parity $0-2$. The frequency of lacerations increased with increasing fetal weight. The only major laceration (third degree) in this study was seen in this age group in a booked woman with parity 1. A similar observation was noted with respect to episiotomies. The episiotomy rate in this study was $20.8 \%$. This rate however, decreased with parity. The relationship between the maternal age, parity, booking status, fetal weight and perineal status at delivery was statistically significant $(\mathrm{P} \leq 0.05)$ (Table 2$)$.

\section{Discussion}

Perineal trauma during childbirth is very common, occurring in about $40 \%$ of women during their first birth and about $20 \%$ in subsequent births. ${ }^{1}$ In this study, only $2(9.5 \%)$ women had minor first degree lacerations while 7(33.3\%) had episiotomy in their first child birth. Obstetrics perineal lacerations are an unavoidable part of vaginal birth and episiotomy as one of the most common surgical procedures in obstetrics is aimed at preventing them. Although episiotomy rate varies from region to region worldwide, it is said to be on the decline in the developed countries but remains high in the developing countries. The episiotomy rate found in this study was $20.8 \%$ which is about one in every five pregnant women and this is more than the World Health Organization recommended rate of $10 \% .{ }^{10}$ It is however lower than the reported frequency of $34.3 \%$ in Ogbomosho ${ }^{3}$ in 2012, 35.6\% in Zaria ${ }^{11}$ in 2003, $39.1 \%$ in Port Harcourt ${ }^{12}$ in 2000 , Abia $45 \%{ }^{13}$ in 2005, Benin $46.6 \%^{14}$ in 1998 and Lagos $54.9 \%{ }^{15}$ all in Nigeria. It is also much lower than the $36.4 \%$ in Cape Town, South Africa and some other African countries. ${ }^{16-17}$ In England the rate of episiotomy fell from over half in 1980 to $37 \%$ in 1985 , and to $20 \%$ in $1995 .{ }^{18}$ Our result compares favorably with this and may reflect the falling trend due to the advocacy and practice of selective episiotomy worldwide for parturients. The rate of episiotomy was highest among the lower age and parity groups of $\leq 20$ to 30 years and primigravida up to parity of 2 respectively (Table 2).This is consistent with the finding of a higher risk of $74 \%$ for episiotomy among adolescents ${ }^{19}$ as a result of their tense muscular tone than their older counterparts leading to a higher likelihood for episiotomy. Threat also increased with the infant birth weight. The booked patients had a significantly higher incidence of episiotomy compared with the unbooked mothers $(\mathrm{P} \leq 0.036)$. This may be due to the desire of the attending personnel to protect the perineum and curb/prevent tears. The procedure should be performed selectively where its absence will result in perineal tear. It has therefore been suggested that the ideal episiotomy rate should be $20-30 \% .^{20}$

On the other hand, frequency of spontaneous laceration in this study was $13.4 \%$ made up of $10.29 \%$ first degree, $3 \%$ second degree and only $1(0.2 \%)$ third degree (severe) lacerations, bringing the combined (episiotomy plus lacerations) incidence of perineal trauma to $34 \%$. This is comparable to other studies which have shown that about one in three women sustain spontaneous laceration in the first childbirth. ${ }^{13}$, ${ }^{21}$ The $0.2 \%$ third degree perineal tears identified is however much less than 0.6-0.9\% third and fourth degree tears reported in the literature. . $^{62}$

The spontaneous laceration rate seen in this study is higher than the $6.9 \%$ spontaneous lacerations observed by Sayiner et al in Eskisehir, Turkey. ${ }^{23}$ Only one case $(0.2 \%)$ of severe (third degree) perineal tear was identified in this study compared with the 0.6$0.9 \%$ reported by other authors, ${ }^{6,22}$ which may involve 
the anal sphincter complex and/or the anal epithelium even in the presence of mediolateral episiotomy. A lower risk of third-degree tear has been found to be associated with a larger angle from the middle of mediolateral episiotomy of up to $50 \%$ reduction for every 6 degrees cut away from the perineal midline. ${ }^{24}$ The trend of spontaneous lacerations followed that of episiotomy by maternal age, parity, booking status and fetal weight.

On the problems of spontaneous lacerations and episiotomy, a retrospective cross-sectional survey of 5 women 12 months after vaginal childbirth found no statistically significant differences in the levels of urinary incontinence and other pelvic floor symptoms in women with an episiotomy and those with first- or second degree perineal trauma and concluded that women with episiotomy have similar perineal morbidity to those with spontaneous laceration. ${ }^{25}$ Although this study did not look at these morbidities after episiotomy and perineal trauma, we are in agreement with the conclusion of the above study due to the similarities in the demographic characteristics of the parturients.

It is obvious from this study that the rates of episiotomy (20.8\%) and perineal laceration (13.4\%) in our center are comparatively low. This may be as a result of the policy of selective use of episiotomy and the early identification of high risk women with fetal macrosomia, malposition, especially persistent occipito-posterior position (as it presents a larger diameter during delivery and is associated with perineal and sphincter injuries) and other conditions. The use of epidural analgesia and destructive vagina procedures as possible risks for episiotomy and perineal tear are a rare occurrence at our center, and therefore did not contribute to the problem under review. The low volume of vaginal deliveries (636) in the 3 years period is in consonance with the presence of many primary, secondary and one other tertiary level hospitals in close proximity to our center where some of the cases may have presented. Furthermore, the delivery of some of the women by nurses and junior level doctors may have produced some inconsistencies in assessment and classification of perineal lacerations seen including those who needed episiotomy.

It was observed during the study that the HIV rate was $81(12.7 \%)$. These may have contributed to lowering the episiotomy rate in the hospital because of the National policy against the use of this method among HIV positive patients in order to reduce the rate of vertical transmission associated with episiotomies. On the other hand, the presence of spontaneous perineal lacerations among HIV positive patients was not included due to the paucity of information available in the records. Other factors that affect the rate of episiotomy and contribute to obstetric perineal lacerations such as gestational age, assisted delivery (forceps \& vacuum), use of routine oxytocin, shoulder dystocia, BM1, prolonged second stage of labor and multifetal pregnancy were not evaluated due to the retrospective nature of this study.

It is recommended that tears should be repaired in theatre (level IV evidence), where there is access to good lighting, appropriate equipment and aseptic condition with the use of general or regional anesthesia for muscle relaxation especially to retrieve the muscle ends. ${ }^{6}$ This recommendation may be directed mainly at patients with major lacerations.

The use of antibiotics, analgesia and most experienced surgeons and the administration of and use of laxatives should be encouraged among women who have undergone a repair especially that involving major degree tears. The use of inexperience staff may contribute to maternal morbidity especially anal incontinence and fistula formation. Therefore all women who have suffered obstetric perineal injury should be counseled at booking and those with symptoms or abnormal anorectic manometric or endoanal ultrasonographic features may be offered elective Caesarean section ${ }^{26}$ as repeat vaginal delivery may worsen symptoms. A previous successful secondary sphincter repair, as opposed to a successful primary repair, should be managed with a pre-labor caesarean section. ${ }^{27}$ There is however, no clear evidence as to the mode of delivery in asymptomatic women.

The perineum of all women should therefore, be supported during the delivery of the fetal head \& shoulder since perineal lacerations occur most commonly during this time. While attempts should be made towards the recognition of risk factors in the mother (precipitate labor, narrow introitus and rigid perineum), fetus (macrosomia, malposition \& malformation) and the prevention of iatrogenic obstetric factors such as extension of episiotomy, posterior episiotomy, uncontrolled labor and assisted vaginal delivery. 


\section{Conclusion}

Information from this study suggests that the relative rate of perineal trauma at birth among women is falling, and the rate of episiotomy and major obstetric perineal lacerations (especially third and fourth degree) in our institution is low compared to other centers in our region. The major risk factors are low parity, low maternal age, and increasing fetal birth weight.

Although episiotomy and spontaneous lacerations may be difficult to predict with certainty especially during the antenatal period and even intrapartum, the presence of risk factors should be an early warning sign to the obstetrician/midwife. This will ensure early anticipation and prompt intervention towards the selective use of episiotomies and the prevention of major lacerations that are likely to affect the quality of life of women.

\section{References}

1. Urato AC, Craigo SD, Chelmow D, O'Brien WF. The association between time of birth and fetal injury resulting in death. Am J Obstet Gynecol. 2006; 195:1521-6.

2. Fyneface-Ogan S, Mato CN, Eyindah CE. Postpartum perineal pain in primiparous women: a comparison of two local anaesthetic agents. Niger J Med. 2006 Jan-March; 15(1):77-80.

3. Alayande BT, Amole IO, Olaolorun DA, Brief communication Relative frequency and predictors of episiotomy in Ogbomoso, Nigeria. Internet Journal of Medical Update 2012 July; 7(2):42-45.

4. Maduma-Butshe A, Dyall A, Garner P. routine episiotomy in developing countries: Time to change a harmful practice. BMJ. 1998 Apr;316(7139):1179-80.

5. Memon H, Handa VL. Vaginal childbirth and pelvic floor disorders. Women's Health.2013. Available from http://www.medscape.org/viewarticle/803448_print.

Accessed on 4/10/2015.

6. RCOG. The management of third-and-fourth-degree perineal tears (Green-top Guidelines No.29). 2007. Available from http://www.reog.org.uk/womens-health/clinicalguidance/management third-and-fourth-degree-perineal-tearsree-top-29.

7. Thacker SB, Banta HD- Benefits and risks of episiotomy: an interpretative review of the English Language Literature, 1860-1980. Obstet Gynaecol Surv 1983; 38: 382-38.

8. Williams A, Tincelle DG, White S, Adams EJ, Alfirevic Z, Richmond DH, Risk scoring system for prediction of Obstetric and Sphincter injury. BJOG 2005; 112: 1066-9.

9. Leeman L, Spearman M, Roger R, Repair of Obstetric Perineal lacerations. Am Farm Physician, 2003;68 (8): 158590.
10. World Health Organization. Care in normal birth, a practical guide 1996 (cited) Available from

http://www.who.int/making-pregnancy-safer/document/whofrh-msm-9624/en/

11. Sule ST, Shittu SO. Puerperal Complications of episiotomies at Ahmadu Bello University Teaching Hospital, Zaria, Nigeria. East Afr Med. J. 2003 Jul; 80(7):351-6.

12. Enyindah CE, Fiebai PO Anya SE et al, Episiotomy and perineal trauma prevalence and obstetric risk factors in Port Harcourt Nigeria. Niger J Med.2007 July-Sep; 16(3):242-5.

13. Chigbu B, Onwere $S$, Aluka $\mathrm{C}$ et al, Factors Influencing the use of episiotomy during vaginal delivery in South Eastern Nigeria East Afr Med. J. 2008 May; 85(5): 240.3.

14. Otoide VO, Ogbonmwan SM, Okonofua FE. Episiotomy in Nigeria. Int. J. Gynaecol Obstet. 2000 Jan; 68(1):13-7.

15. Ola ER, Bello O. Abudu OO et al. Episiotomies in Nigeria should their use be restricted? Niger Postgrad Med. J. 2002Mar; 9(1):13-6.

16. Lorenz N, Nougtara A, Garner P. Episiotomies in Burkina Faso, Trop Doct. 1998 Apri; 28(2):83-5.

17. Thompson A. Episiotomies should not be routine: Safe Motherhood Newsletter, Genera; WHO.1997; 12.

18. Maduma-Butshe A, Dyall A, Garner P. Routine episiotomy in developing countries: Time to change a harmful practice. BMJ 1998 Apri; 28(2):316 (7139):1179-80.

19. Carvalho CC, Saiza AS, Moraes Fill OB. Prevalence and factors associated with practice of episiotomy at a maternity school in Recife, Pernambuco, Brazil. Rev Asso Med Bras. 2010 May-Jun; 56(3): 333-9.

20. Fernando JF, Sultan Att. Risk factors and management of Obstetric Perineal injury. Curr Obst Gynaecol 2004; 14:3206.

21. Imarengiaye $\mathrm{CO}$, Andet $\mathrm{AB}$. Postpartum perineal pain among Nigerian women. West Afr J Med. 2008; 27(3): 148-51.

22. Juul L, Theron GB. Risk factors for third-and-fourth-degree perineal tears during vaginal delivery. The Urogynaecologia International Journal 2011. Available from http://www.urogynaecologin.org/index.Php/uij/article/view/u ij.2011.

23. Sayiner F, Ozordogan N, Tozun M, Ciray S, Koseroglu N, Unsal A: The effect of post-partum perineal trauma on the frequencies perineal pain, urinary incontinence and dypareunia. The Internet Journal of Epidemiology, 2010 Volume 8 number 1.

24. Eogan M, Daly I O'Connell PA, O'Hertity C. Does the angle of episiotomy affect the incidence of anal sphincter injury? BJOG 2006; 113:190-4.

25. Williams A, Herron-Max S, Carolyn H. The prevalence of enduring postnatal perineal morbidity and its relationship to perineal trauma. Midwifery 2007; 23(4), 392-403.

26. Sultan $\mathrm{AH}$, Thaker R. lower genital tract and sphincter trauma. Best Pract. Res. Clin Obstet Gynaecol 2002; 16:99115 .

27. James DK, Steer PJ Weiner CP, Gonik B. High Risk Pregnancy Management Options, $3^{\text {rd }}$ ed.2005 Sounders Elseview, Amsterdam The Netherlands. 